\title{
Prediction of Oral Absorption of Low-Solubility Drugs by Using Rat Simulated Gastrointestinal Fluids: The Importance of Regional Differences in Membrane Permeability and Solubility
}

\author{
Yusuke Tanaka, Toshiyuki Baba, Koji Tagawa, Ryoichi Waki, Shunji Nagata \\ Laboratory of Pharmaceutical Technology, Faculty of Pharmaceutical Sciences, Hiroshima International University, \\ 5-1-1 Hiro-koshingai, Kure, Hiroshima, Japan
}

Received, November 24, 2013; Revised, March 3, 2014; Accepted, March 5, 2014; Published, March 7, 2014.

\begin{abstract}
Purpose. This study aimed to develop a novel approach for predicting the oral absorption of low-solubility drugs by considering regional differences in solubility and permeability within the gastrointestinal (GI) tract. Methods. Simulated GI fluids were prepared to reflect rat in vivo bile acid and phospholipid concentrations in the upper and lower small intestine. The saturated solubility and permeability of griseofulvin (GF) and albendazole (AZ), a drug with low aqueous solubility, were measured using these simulated fluids, and fraction absorbed $(\mathrm{Fa})$ at time $t$ after oral administration was calculated. Results. The saturated solubility of GF and AZ, a drug with low aqueous solubility, differed considerably between the simulated GI fluids. Large regional differences in drugs concentration were also observed following oral administration in vivo. The predicted $\mathrm{Fa}$ values using solubility and permeability data of the simulated GI fluid were found to correspond closely to the in vivo data. Conclusion. These results indicated the importance of evaluating regional differences in drug solubility and permeability in order to predict oral absorption of low-solubility drugs accurately. The new methodology developed in the present study could be useful for new oral drug development.
\end{abstract}

This article is open to POST-PUBLICATION REVIEW. Registered readers (see "For Readers") may comment by clicking on ABSTRACT on the issue's contents page.

\section{INTRODUCTION}

Prediction and assessment of human oral absorption of drug candidates at the preclinical phase is very important for the development of oral products, and there is a global research effort in this area (1-4). Dissolution is the first step in oral absorption of solid drugs such as tablets and capsules. Bile acid and phospholipid concentrations in the gastrointestinal (GI) tract are important factors influencing the dissolution rate, solubility, and membrane permeability of drugs especially low soluble drugs, because of their influence on micellization (5-7). Various simulated GI fluids, including bile acids and phospholipids, have been developed to predict and assess drug solubility and membrane permeability in the GI tract (8-11). However, these simulated GI fluids were prepared according to the composition of the upper small intestinal fluid in humans and dogs. We have previously reported large regional differences in total bile acid and phospholipid concentrations between the upper and lower small intestine in rats (12). In order to increase the accuracy of prediction of in vivo oral absorption, the in vitro or in situ data related to solubility and permeability must be generated under conditions that are as close as possible to those in vivo. Therefore, evaluating the dissolution and solubility of drugs in the lower region of the GI tract, as well as the upper small intestine, is very important for accurate prediction of oral bioavailability. This is particularly important for poorly water-soluble drug candidates, because dissolution and solubility of these compounds are strongly influenced by regional differences in bile acid and phospholipid concentrations. Fotaki et al. and Jantratid et al. used media simulating human proximal colon and ileum fluids to evaluate the dissolution of drugs in these regions $(\mathbf{1 3}, \mathbf{1 4})$. Although these media were prepared to match the osmolality, buffering capacity, and ionic strength of actual GI fluids, the bile acids and phospholipids concentration might not be adjusted to in vivo,

Corresponding Author: Yusuke Tanaka Laboratory of Pharmaceutical Technology, Faculty of Pharmaceutical Sciences, Hiroshima International University, Kure, Hiroshima, Japan; E-mail: y-tanaka@ps.hirokoku-u.ac.jp 
because it might be assumed that bile acids and phospholipids were completely absorbed or degraded in these regions.

When intestinal drug concentration reaches and sustains its saturated solubility level, the amount absorbed can be expressed as a product of this drug saturated solubility, the intestinal membrane permeability, the surface area of the intestine, and the drug residence time $(\mathbf{1 5}, \mathbf{1 6})$. The amount of drug absorbed estimated in this way is known as the maximum absorbable dose (MAD), because the drug is assumed to maintain saturated drug solubility throughout its transit through the GI tract. When the dose-to-luminal volume ratio is higher than the solubility of the drug (dose number) and the dissolution rate is greater than the absorption rate across the GI membrane, drug absorption is limited by solubility and not by the dissolution rate $(\mathbf{1 7}, \mathbf{1 8})$. This solubility-limited absorption is often observed when poorly water-soluble drugs are administered orally. The equation to estimate MAD is therefore considered very useful for the evaluation and/or prediction of the oral absorption of low-solubility drugs.

In this study, fasted state simulated rat intestinal fluids were formulated based on information about total bile acid and phospholipid concentrations in the upper and lower small intestines (12). Using these, a novel method for predicting oral absorption of a drug with low aqueous solubility was developed. This method used the MAD equation and took into account regional differences in drug solubility and intestinal membrane permeability within the GI tract.

\section{MATERIALS AND METHODS}

\section{Materials}

Albendazole (AZ) was purchased from Tokyo Kasei Kogyo Co., Ltd. (Tokyo, Japan). Griseofulvin
(GF), albendazole sulfoxide (AZSO; an active metabolite of AZ), egg-lecithin and sodium taurocholate were purchased from WAKO Pure Chemical Industries, Ltd. (Osaka, Japan). All other reagents were analytical-grade commercial products.

\section{Preparation of fasted state simulated GI fluids}

The simulated GI fluid compositions are summarized in Table 1. Isotonic phosphate buffers (pH 7.0) were prepared by mixing $2.54 \%$ $\mathrm{NaH}_{2} \mathrm{PO}_{4} \cdot 2 \mathrm{H}_{2} \mathrm{O}$ and $4.41 \% \mathrm{Na}_{2} \mathrm{HPO}_{4} \cdot 12 \mathrm{H}_{2} \mathrm{O}$. Then, distilled water was added to the $\mathrm{pH} 7.0$ phosphate buffer solution in the ratio of $4: 16$ or $6.8: 13.2$. Sodium taurocholate and egg-lecithin were dissolved in phosphate buffer diluted with water at $4: 16$ or $6.8: 13.2$ to prepare simulated upper GI tract fluid (FaSSIF rat, upper) or lower GI tract fluid $\left(\mathrm{FaSSIF}_{\text {rat lower }}\right)$, respectively. The osmotic pressures of FaSSIF rat, upper and FaSSIF rat, lower were 280-290 $\mathrm{mOsmol} / \mathrm{kg}$ (OSMOMAT, 030-3P, GONOTEC $\mathrm{GmbH}$, Germany).

\section{Prediction of fraction absorbed (Fa) at time $t$}

The amount of drug absorbed from the GI tract at time $\mathrm{t}$ under solubility-limited conditions was estimated using the following equation $(\mathbf{1 5}, \mathbf{1 6})$ :

Amount absorbed at time $\mathrm{t}$

$\left(\mathrm{Xa}_{\mathrm{t}}\right)=\mathrm{P} \times \mathrm{Cs} \times \mathrm{S} \times \mathrm{t}$

$\mathrm{P}, \mathrm{Cs}, \mathrm{S}$, and $\mathrm{t}$ are the intestinal membrane permeability, the saturated drug solubility in intestinal fluid, the intestinal surface area, and the drug duration time in the GI tract, respectively. In order to consider the regional differences in each parameter, the GI tract was divided into two segments (the upper small intestine and lower small

Table 1. The composition of FaSSIF rat, upper and FaSSIF rat, lower

$\begin{array}{cc}\text { Sodium } & \text { Egg- } \\ \text { taurocholate } & \text { lecithin } \\ (\mathrm{mM}) & (\mathrm{mM})\end{array}$

$\begin{array}{lccc}\text { FaSSIF }_{\text {rat, upper }} & 50 & 3.7 & 7.0 \\ \text { FaSSIF }_{\text {rat, lower }} & 100 & 0.1 & 7.0\end{array}$

The bile acid and phospholipids concentrations and $\mathrm{pH}$ were referred to previous report (12). 
intestine), and the drug absorption from each segment at time $t$ was calculated using the relevant $\mathrm{P}, \mathrm{Cs}, \mathrm{S}$, and t of that GI segment. The total amount absorbed at time $t$ from the whole small intestine was estimated using the sum of the absorbed amounts at time $t$ from each segment, as shown below.

Total amount absorbed at time $\mathrm{t}$

$\left(\mathrm{Xa}_{\text {total }, \mathrm{t}}\right)=\mathrm{Xa}_{\text {upper }, \mathrm{t}}+\mathrm{Xa}_{\text {lower }, \mathrm{t}}=\mathrm{P}_{\text {upper }} \times \mathrm{Cs}_{\text {upper }} \times$

$\mathrm{S}_{\text {upper }} \times \mathrm{t}_{\text {upper }}+\mathrm{P}_{\text {lower }} \times \mathrm{CS}_{\text {lower }} \times \mathrm{S}_{\text {lower }} \times \mathrm{t}_{\text {lower }}$

Where $\mathrm{Xa}_{\text {upper, }}, \mathrm{P}_{\text {upper }}, \mathrm{Cs}_{\text {upper, }}, \mathrm{S}_{\text {upper, }}, \mathrm{t}_{\text {upper }}$ and $\mathrm{Xa} \mathrm{a}_{\text {lower, }}$ t, $\mathrm{P}_{\text {lower, }}, \mathrm{Cs}_{\text {lower }}, \mathrm{S}_{\text {lower, }}$ and $\mathrm{t}_{\text {lower }}$ are the amount of drug absorbed at time $t$, the GI membrane permeability, the saturated drug solubility, the GI membrane surface area, and the duration time of saturated drug solubility in the upper small intestine and lower small intestine, respectively. The predicted $\mathrm{Fa}$ value of a drug at time $\mathrm{t}\left(\mathrm{Fa}_{\text {predicted, }} \mathrm{t}\right)$ was then estimated by dividing $\mathrm{Xa}_{\text {total, }} \mathrm{t}$ by the dose.

$\mathrm{Fa}_{\text {predicted, } \mathrm{t}}=\mathrm{Xa} \mathrm{a}_{\text {total, } \mathrm{t}} /$ Dose

Saturated solubility measurement of GF and AZ in simulated GI fluids

Saturated GF and AZ solubility in FaSSIF $_{\text {rat, upper }}$ and $\mathrm{FaSSIF}_{\text {rat, lower }}$ was measured to provide values for $\mathrm{Cs}_{\text {upper }}$ and $\mathrm{Cs}_{\text {lower, }}$ respectively. Excess GF or AZ was suspended in $\mathrm{FaSSIF}_{\text {rat, upper }}$ and FaSSIF $\mathrm{Fat}_{\text {, lower, }}$ and vortexed. Each sample was then shaken in an incubator at $37^{\circ} \mathrm{C}$ for $24 \mathrm{~h}$. The resulting suspensions were filtered through $0.45-\mu \mathrm{m}$ cellulose membranes before analyzing GF and $\mathrm{AZ}$ in the supernatant by high-performance liquid chromatography (HPLC).

\section{Measurement of the rat small intestine length}

All animal studies were conducted in accordance with the Guidelines for the Care and Use of Laboratory Animals of the Committee for Animal Experiments of Hiroshima International University. The whole small intestine (from the pyloric sphincter to the ileocecal valve) was removed. The length was directly measured using a ruler. This length was used to calculate the surface area in each GI region ( $\mathrm{S}_{\text {upper }}$ and $\left.\mathrm{S}_{\text {lower }}\right)$.

In situ measurement of the apparent permeability of GF and $\mathrm{AZ}$

The apparent permeability of GF and AZ in the upper and lower small intestine $\left(\mathrm{P}_{\text {upper }}\right.$ and $\left.\mathrm{P}_{\text {lower }}\right)$ was measured using the in situ closed loop method. $\mathrm{GF}$ and $\mathrm{AZ}$ was dissolved in $\mathrm{FaSSIF}_{\text {rat, upper }}$ and

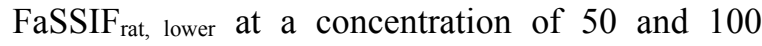
$\mu \mathrm{g} / \mathrm{mL}$ for $\mathrm{GF}$ and 8 and $16 \mu \mathrm{g} / \mathrm{mL}$ for $\mathrm{AZ}$, respectively. Each drug solution $(1 \mathrm{~mL} / 10 \mathrm{~cm})$ was injected into the corresponding GI segment, and both ends were ligated to make intestinal loops. After a period of time, the luminal solution was collected. The amount absorbed was calculated by subtracting the amount remaining from the original amount in the loop. The apparent GF and AZ permeability in each GI segment ( $\mathrm{P}_{\text {upper }}$ and $\left.\mathrm{P}_{\text {lower }}\right)$ was evaluated using the following equation (19).

$\mathrm{P}=\mathrm{kaV} / 2 \pi \mathrm{RL}$

Where $\mathrm{ka}$ is the drug absorption rate constant estimated from the absorbed amount during the defined period, assuming that drug absorption follows first-order kinetics; $\mathrm{V}$ is the volume of drug solution injected into each loop; and $\mathrm{R}$ is the radius of the GI tract $(0.18 \mathrm{~cm}$ for the upper and lower small intestine (20). L is the length of GI tract used in this experiment.

\section{In vivo measurement of luminal and plasma drug concentrations}

$\mathrm{GF}$ and $\mathrm{AZ}$ powders were suspended in $0.5 \%$ methylcellulose 50 solutions at 25 and $3.5 \mathrm{mg} / \mathrm{mL}$, respectively. After oral administration of $1 \mathrm{~mL}$ drug suspension to fasted rats (210-240 g), they were killed at the time points indicated. The abdomen was then opened immediately to collect samples of luminal fluid from the stomach, upper small intestine (from a site 5 to $30 \mathrm{~cm}$ distal to the stomach), and lower small intestine (from a site 5 to $30 \mathrm{~cm}$ proximal to the cecum), by using a micropipette. To sample colonic fluid, luminal contents of the rectum and colon were collected using a microspatula due to the very small amount of colonic fluid. These samples were then immediately filtered through $0.65-\mu \mathrm{m}$ hydrophilic polyvinylidene fluoride (PVDF) centrifugal filter units (Ultrafree ${ }^{\circledR}$, Millipore Corporation, USA), and the filtrates were regarded as a luminal fluid. The filtrates were weighed and the volumes were calculated by assuming a relative density of 1 . The filtrates were then diluted with $10 \%$ methanol for GF and 25\% dimethyl sulfoxide (DMSO) solution for AZ. Adsorption of AZ to the microtube surface because of high hydrophobicity can be avoided by 
adding DMSO.

Blood samples $(1 \mathrm{~mL})$ were taken from the jugular vein at the same time as the GI fluid sampling. Portal blood samples were also taken in a group of rats administered GF suspension. Plasma was obtained by centrifugation and de-proteinized by acetonitrile precipitation. After centrifugation, the resulting supernatant was evaporated prior to resuspension in the HPLC mobile phase for GF and $20 \%$ DMSO solution for AZSO and determination of GF and AZSO concentration by using HPLC. After intestinal absorption, almost $100 \%$ of $\mathrm{AZ}$ is rapidly oxidized into its pharmacologically active metabolite, AZSO, in the mucosal cells and the liver and subsequently AZSO converted into the inactive metabolite albendazole sulfone $(\mathbf{2 1}, \mathbf{2 2})$. Hence, the AZSO concentration was quantified for the evaluation of oral $\mathrm{AZ}$ absorption.

\section{Measurement of the saturated solubility of $A Z$ in the upper and lower intestinal fluid samples from each segment of the rat GI tract}

Upper and lower intestinal fluids were taken from rat GI tract. Then, excess AZ was suspended in each luminal fluid sample and was vortexed sufficiently. Then, each sample was shaken in an incubator at $37^{\circ} \mathrm{C}$ for $3 \mathrm{hr}$. The suspension was filtered through a $0.65 \mu \mathrm{m}$ hydrophilic polyvinylidene fluoride membrane (Millipore Corporation, USA). The supernatant was analyzed by HPLC.

\section{In vivo oral and intravenous (i.v.) administration} GF powder was dissolved in $60 \%$ polyethyleneglycol 400 (PEG400) solution at a concentration of 1 or $0.5 \mathrm{mg} / \mathrm{mL}$. Then, $0.5 \mathrm{~mL}$ of 1 $\mathrm{mg} / \mathrm{mL}$ GF solution was administered i.v. to fasted rats $(210-240 \mathrm{~g})$ via the jugular vein $(0.5 \mathrm{mg} /$ body $)$ and $1 \mathrm{~mL}$ of $0.5 \mathrm{mg} / \mathrm{mL}$ GF solution was administered orally $(0.5 \mathrm{mg} /$ body $)$. AZSO powder was dissolved 40\% PEG400 and 10\% DMSO solution at a concentration of $0.5 \mathrm{mg} / \mathrm{mL}$, and then the $0.4 \mathrm{~mL}(0.2 \mathrm{mg} /$ body $)$ was injected via the jugular vein. Femoral artery blood samples were obtained periodically via a cannula. Plasma was prepared by centrifugation and de-proteinized by acetonitrile precipitation. After centrifugation, the resulting supernatant was evaporated and then resuspended in the HPLC mobile phase and 20\% DMSO solution for GF and AZSO, respectively. The drug concentration in each sample was then analyzed using HPLC.
Measurement of portal plasma concentration after oral administration of GF solution

GF solution $(0.5 \mathrm{mg} / \mathrm{mL}, 1 \mathrm{~mL})$ with $60 \%$ PEG400 was administered orally to fasted rats. Then, the rats were killed periodically, and the abdomen was opened. Blood samples were taken from the portal vein and centrifuged to obtain plasma samples. After de-proteinization by acetonitrile precipitation, the resulting supernatant was evaporated prior to resuspension in the HPLC mobile phase and determination of GF concentration by using HPLC.

\section{Calculation of the in vivo $\mathrm{Fa}$}

In the case of GF, $\mathrm{BA}_{\text {suspension }}$ at time $\mathrm{t}\left(\mathrm{BA}_{\text {suspension, }} \mathrm{t}\right)$ was estimated from the time-course of oral bioavailability (BA) which was calculated by a deconvolution method using the plasma GF concentrations after oral administration of $25 \mathrm{mg}$ GF suspension and after i.v. administration of GF solution. The fraction GF absorbed after oral administration of suspension at time $\mathrm{t}\left(\mathrm{Fa}_{\text {suspension, } \mathrm{t}}\right)$ was calculated as shown below.

$$
\begin{aligned}
& \mathrm{BA}_{\text {solution }}=\mathrm{AUC}_{0-\infty, \text { solution }} / \mathrm{AUC}_{0-\infty, \mathrm{i} . \mathrm{v} .} \times \\
& \text { Dose }_{\mathrm{i} . \mathrm{v}} / \mathrm{Dose}_{\text {solution }} \times 100 \\
& =\mathrm{Fa}_{\text {solution }} \times \mathrm{Fg}_{\text {solution }} \times \mathrm{Fh}_{\text {solution }} \times 100 \\
& =\mathrm{Fg}_{\text {solution }} \times \mathrm{Fh}_{\text {solution }} \times 100 \\
& \mathrm{Fa}_{\text {suspention, } \mathrm{t}}=\mathrm{BA}_{\text {suspension, } \mathrm{t}} / \mathrm{BA}_{\text {solution }} \\
& =\left(\mathrm{Fa} \mathrm{F}_{\text {suspension, } \mathrm{t}} \times \mathrm{Fg}_{\text {suspension }} \times \mathrm{Fh}_{\text {suspension }}\right) /\left(\mathrm{Fg}_{\text {solution }} \times\right. \\
& \left.\mathrm{Fh}_{\text {solution }}\right)
\end{aligned}
$$

$\mathrm{AUC}_{0-\infty}$, solution and $\mathrm{AUC}_{0-\infty}$, i.v. refer to the areas under the curve of the plasma GF concentration time-course from $0 \mathrm{~h}$ to infinite time after oral or i.v. administration of GF solutions, respectively. The AUC from $0 \mathrm{~h}$ to infinite time $\left(\mathrm{AUC}_{0-\infty}\right)$ was calculated by extrapolation using several points of terminal plasma drug concentrations in the time-profiles.

The $\mathrm{Fa}_{\text {solution }}$ (fraction absorbed after oral administration of GF solution) was regarded as 1, because the drug was administered as a solution and could therefore be completely absorbed from the GI tract because of the high permeability. If linear drug metabolism kinetics in the GI mucosa $(\mathrm{Fg})$ and the liver (Fh) were assumed for both administrations of solution $\left(\mathrm{Fg}_{\text {solution }}\right.$ and $\mathrm{Fh}_{\text {solution, }}$ respectively) and suspension ( $\mathrm{Fg}_{\text {suspension }}$ and

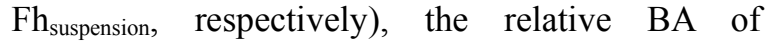
$\mathrm{BA}_{\text {suspension, } t}$ to $\mathrm{BA}_{\text {solution }}$ gave the $\mathrm{Fa}_{\text {suspension, } \mathrm{t}}$. However, if non-linearity was observed in 
$\mathrm{Fg}_{\text {suspension }}$ and $\mathrm{Fh}_{\text {suspension }}$ in the administration of the GF suspension, due to the much higher dose than the solution, the $\mathrm{Fa}_{\text {suspension, } \mathrm{t}}$ becomes the apparent value multiplied by the increasing rate of $\left(\mathrm{Fg}_{\text {suspension }} \times \mathrm{Fh}_{\text {suspension }}\right) /\left(\mathrm{Fg}\right.$ solution $\left.\times \mathrm{Fh}_{\text {solution }}\right)$. Therefore, in order to correct the apparent value to the true $\mathrm{Fa}_{\text {suspension, } \mathrm{t} \text { value, }} \mathrm{Fh}_{\text {suspension }} / \mathrm{Fh}_{\text {solution was }}$ calculated as follows.

$\mathrm{Fa} \times \mathrm{Fg}=\mathrm{Q}_{\mathrm{pv}} \times \mathrm{Rb} \times\left(\mathrm{AUC}_{\mathrm{pv}}-\mathrm{AUC}_{\mathrm{sys}}\right) /$ Dose

Where $\mathrm{Qpv}_{\mathrm{pv}}, \mathrm{Rb}, \mathrm{AUC}_{\mathrm{pv}}$, and $\mathrm{AUC}_{\mathrm{sys}}$ are the portal blood flow, the blood/plasma concentration ratio, AUC in the portal vein, and AUC in the systemic circulation, respectively $(\mathbf{2 3}, \mathbf{2 4})$.

$\mathrm{Fh}_{\text {suspension }}$ and $\mathrm{Fh}_{\text {solution }}$ can be calculated by equations (10) and (11).

$\mathrm{Fh}_{\text {suspension }}=\mathrm{BA}_{\text {suspension }} /\left(\mathrm{Fa}_{\text {suspension }} \times \mathrm{Fg}_{\text {suspension }}\right)$

$=\mathrm{BA}_{\text {suspension }} /\left(\mathrm{Q}_{\mathrm{pv}} \times \mathrm{Rb} \times\left(\mathrm{AUC}_{0-\infty}\right.\right.$, suspension, pv -

$\mathrm{AUC}_{0-\infty}$, suspension, sys $) /$ Dose) (10)

$\mathrm{Fh}_{\text {solution }}=\mathrm{BA}_{\text {solution }} /\left(\mathrm{Fa}_{\text {solution }} \times \mathrm{Fg}_{\text {solution }}\right)$

$=\mathrm{BA}_{\text {solution }} /\left(\mathrm{Q}_{\mathrm{pv}} \times \mathrm{Rb} \times\left(\mathrm{AUC}_{0-\infty}\right.\right.$, solution, pv $-\mathrm{AUC}_{0-\infty}$,

solution, sys $) /$ Dose)

Where $\mathrm{AUC}_{0-\infty}$, suspension, $\mathrm{pv}, \mathrm{AUC}_{0-\infty}$, suspension, sys, $\mathrm{AUC}_{0-\infty}$, solution, pv and $\mathrm{AUC}_{0-\infty}$, solution, sys are the $\mathrm{AUC}$ at time $0 \mathrm{~h}$-infinity in the portal vein and systemic circulation after oral administration of GF suspension and solution, respectively.

$\mathrm{Fh}_{\text {suspension }} / \mathrm{Fh}_{\text {solution }}$ were estimated using equations (10) and (11).

$\mathrm{Fh}_{\text {suspension }} / \mathrm{Fh}_{\text {solution }}$

$=\left(\mathrm{BA}_{\text {suspension }} /\left(\left(\mathrm{AUC}_{0-\infty}\right.\right.\right.$, suspension, pv $-\mathrm{AUC}_{0-\infty \text {, suspension, }}$ sys)/Dose $)) /$

$\left(\mathrm{BA}_{\text {solution }} /\left(\left(\mathrm{AUC}_{0-\infty}\right.\right.\right.$, solution, pv $-\mathrm{AUC}_{0-\infty}$, solution, sys)/Dose))

$\mathrm{Q}_{\mathrm{pv}}$ and $\mathrm{Rb}$ were assumed to be the same value in the administrations of both GF suspension and solution.

$\mathrm{Fa}_{\text {suspension, } \mathrm{t}}$ was corrected by dividing by the $\mathrm{Fh}_{\text {suspension }} / \mathrm{Fh}_{\text {solution. }}$.

$\mathrm{Fa}_{\text {suspension, } \mathrm{t} \text {, cor. }}=\mathrm{Fa}_{\text {suspension, } \mathrm{t}} \mathrm{t}\left(\mathrm{Fh}_{\text {suspension }} / \mathrm{Fh}_{\text {solution }}\right)(13)$

In the case of $\mathrm{AZ}$, in vivo $\mathrm{Fa}$ of $\mathrm{AZ}$ was estimated in the almost same way depicted in equations (5) and (8). In the present study, BA of AZ was defined as the rate of AZSO amount reaching systemic circulation to oral AZ dosage, because the first-pass effect of AZ into AZSO is almost $100 \%$ (21, 22). Deconvolution using the AZSO plasma concentration after oral administration of $3.5 \mathrm{mg}$ of $\mathrm{AZ}$ as suspension and i.v. administration of $0.2 \mathrm{mg}$ of AZSO gives BA of $\mathrm{AZ}$ at each time point $\left(\mathrm{BA}_{\text {suspension, } \mathrm{t}}\right)$. $\mathrm{BA}_{\text {solution }}$ calculated using $\mathrm{AUC}_{0-\infty}$, solution after oral administration of $\mathrm{AZ}$ as solution and $\mathrm{AUC}_{0-\infty}$, i.v. after i.v. administration of AZSO provides $\mathrm{Fg} \times$ Fh of AZSO in the first pass, because AZ administered as solution is completely absorbed from the GI tract due to the high permeability as with GF. If AZSO is not metabolized in the first pass at all, the $\mathrm{AUC}_{0-\infty}$, solution become equal to $\mathrm{AUC}_{0-} \infty$, i.v when the doses in the both administrations are same. Hence, the relative BA of $\mathrm{BA}_{\text {suspension, } \mathrm{t}}$ to $\mathrm{BA}_{\text {solution }}$ gave the $\mathrm{Fa}_{\text {suspension, } \mathrm{t}}$ of $\mathrm{AZ}$. These calculations were conducted after converting the unit of dose $(\mathrm{mg})$ and plasma concentration $(\mu \mathrm{g} / \mathrm{mL})$ to molar unit.

\section{HPLC analysis}

HPLC with a pump (LC-20AD, Shimadzu Corporation, Kyoto, Japan) and a UV detector (SPD-20A, Shimadzu Corporation, Kyoto, Japan) was used for quantification of GF, AZ and AZSO. Column oven was set at $40{ }^{\circ} \mathrm{C}$. An analytical column (YMC-Pack Pro C18; $150 \times 6.0$ mm I.D.; YMC Co., Ltd. Japan) was used for GF and AZ. The mobile phases consisted of $50 \mathrm{mM}$ phosphate buffer $(\mathrm{pH}, 6.0$ for $\mathrm{GF}$ and $\mathrm{pH}, 2.5$ for $\mathrm{AZ})$ and acetonitrile in a ratio of $11: 9$ and $6: 4(\mathrm{v} / \mathrm{v})$ for GF and AZ, respectively. The concentration of AZSO in the plasma samples was determined using a Zorbax Eclipse XDB-C18 column $(2.1 \times 50 \mathrm{~mm}$, I.D., $5 \mu \mathrm{m}$, Agilent Technologies). The mobile phases consisted of $50 \mathrm{mM}$ phosphate buffer $(\mathrm{pH}$, 4.0) and acetonitrile in a ratio of 9:1. GF, AZ, and AZSO were detected at 293, 310, and $292 \mathrm{~nm}$, respectively.

\section{RESULTS}

Solubility of GF and AZ in FaSSIF rat, upper and FaSSIF rat, lower

FaSSIF $_{\text {rat, }}$ upper and $\mathrm{FaSSIF}_{\text {rat, lower, were prepared }}$ based on the total bile acid, phospholipid concentrations and $\mathrm{pH}$ found in the upper and lower small intestine (Table 1) (12). The saturated solubility of GF and AZ in each simulated GI fluid (Csupper and Cslower) is shown in Fig. 1A and B. 
These values were 104.6 \pm 6.5 , and $230.0 \pm 13.3$ $\mu \mathrm{g} / \mathrm{mL}$ for $\mathrm{GF}$ and $14.9 \pm 0.31$, and $35.0 \pm 0.77$ $\mu \mathrm{g} / \mathrm{mL}$ for $\mathrm{AZ}$ in FaSSIF rat, upper $_{\text {and }} \mathrm{FaSSIF}_{\text {rat, lower, }}$ respectively. It is considered that the difference in the solubility values in $\mathrm{FaSSIF}_{\text {rat, upper }}$ and $\mathrm{FaSSIF}_{\text {rat, }}$ lower depends on the taurocholic acid concentration in each simulated GI fluid. The saturated solubility of GF and $\mathrm{AZ}$ in $\mathrm{FaSSIF}_{\text {rat, upper }}$ and $\mathrm{FaSSIF}_{\text {rat, lower }}$ were almost the same values as those in in vivo rat upper and lower jejunal fluids (122.4 \pm 42.0 and $213.0 \pm 85.1 \mu \mathrm{g} / \mathrm{mL}$ for GF (12), and $14.0 \pm 6.92$ and $30.8 \pm 13.3 \mu \mathrm{g} / \mathrm{mL}$ for $\mathrm{AZ}$, respectively). Therefore, the developed simulated GI fluids correlated well with in vivo solubility behavior.

\section{Apparent surface area and permeability of each GI tract}

The length of the small intestine was $72.2 \pm 6.1 \mathrm{~cm}$. In the present study, the lengths of the upper and lower small intestine were defined as $36.1 \mathrm{~cm}$ by dividing in the middle of the small intestine. The apparent surface area of each GI segment was calculated as $40.8 \mathrm{~cm}^{2}$ for the upper and lower small intestine $\left(\mathrm{S}_{\text {upper }}\right.$ and $\left.\mathrm{S}_{\text {lower }}\right)$ by using a radius of $0.18 \mathrm{~cm}$ (Table 2) (20).

The drug permeability in each GI region estimated by using the corresponding simulated GI fluid ( $\mathrm{P}_{\text {upper }}$ and $\mathrm{P}_{\text {lower }}$ ) was $3.4 \pm 0.35$ and $3.2 \pm$ $0.32 \times 10^{-5} \mathrm{~cm} / \mathrm{s}$ for GF and $3.2 \pm 0.18$ and $4.0 \pm$ $1.0 \times 10^{-5} \mathrm{~cm} / \mathrm{s}$ for $\mathrm{AZ}$, respectively.

A.

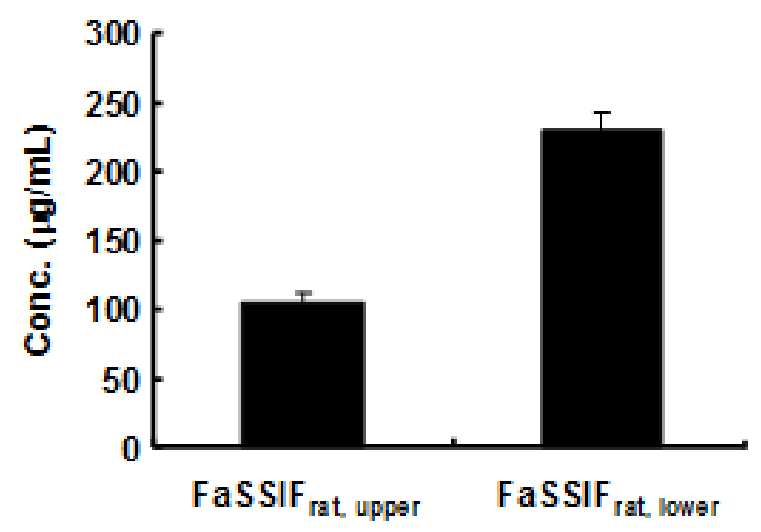

Estimation of the duration of saturated GF and AZ solubility in each GI tract region

Luminal GF and AZ concentrations were measured to quantify the duration time of the saturated solubility of GF and AZ in the upper small intestine $\left(t_{\text {upper }}\right)$ and lower small intestine ( $\left.t_{\text {lower }}\right)$ (Figs. 2 and 3). The solid and dotted lines in Figs. 2 and 3 show the saturated solubility and the standard deviation in in vivo upper and lower small intestinal fluids. The GF concentration in the stomach $0.5 \mathrm{~h}$ after oral administration of $25 \mathrm{mg}$ GF suspension was approximately $20.5 \mu \mathrm{g} / \mathrm{mL}$, and this concentration decreased gradually with time. The luminal concentration in the upper and lower small intestine showed the saturated solubility for 2.5 and $3 \mathrm{~h}$, respectively. Therefore, the duration time of the GF saturated solubility was $0-2.5 \mathrm{~h}$ for the upper small intestine, and $0-3.0 \mathrm{~h}$ for the lower small intestine. In $\mathrm{AZ}$, the $\mathrm{AZ}$ concentration in the stomach reached about $100 \mu \mathrm{g} / \mathrm{mL}$ at highest. The concentration was much higher than those in the upper or lower small intestine, because $A Z$ shows basic properties (25). However, no supersaturation phenomenon of AZ in upper small intestine was observed due to rapid precipitation. The luminal AZ concentration in the upper and lower small intestine showed the saturated solubility for 1.0 and $2.5 \mathrm{~h}$, respectively. Therefore, the duration time of the AZ saturated solubility was decided as $0-1.0 \mathrm{~h}$ for the upper small intestine, and $0-2.5 \mathrm{~h}$ for the lower small intestine. The $\mathrm{AZ}$ concentration in upper small intestine increased again at $4 \mathrm{~h}$ (Fig. 3).

\section{B.}

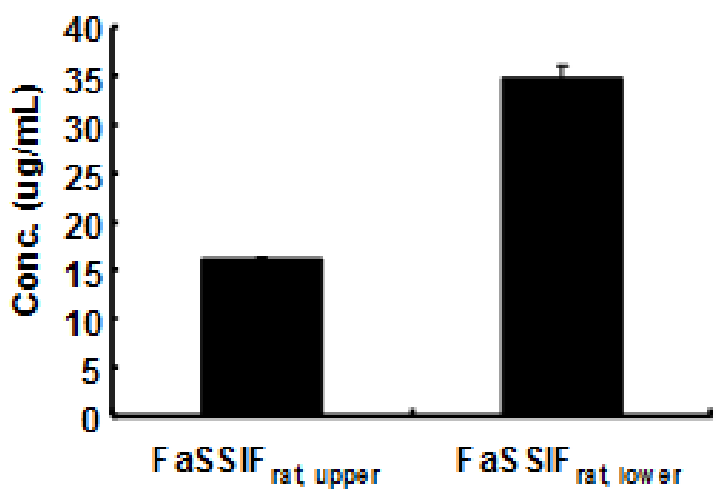

Figure 1. The GF (A) and AZ (B) solubility in FaSSIF rat, upper and FaSSIF rat, lower* The results are expressed as the mean $\pm \mathrm{SD}(\mathrm{N}=64)$. 
Table 2. Apparent surface area $(\mathrm{N}=7)$ and permeability of $\mathrm{GF}(\mathrm{N}=5)$ and $\mathrm{AZ}(\mathrm{N}=4)$ in each $\mathrm{GI}$ segment

\begin{tabular}{|c|c|c|c|}
\hline \multirow{2}{*}{ GI segments } & \multirow{2}{*}{ Surface area $\left(\mathrm{cm}^{2}\right)$} & \multicolumn{2}{|c|}{ Permeability $\pm \mathrm{SD} \quad\left(\times 10^{-5} \mathrm{~cm} / \mathrm{sec}\right)$} \\
\hline & & GF & $\mathrm{AZ}$ \\
\hline Upper small intestine & 40.8 & $3.4 \pm 0.35$ & $3.2 \pm 0.18$ \\
\hline Lower small intestine & 40.8 & $3.2 \pm 0.32$ & $4.0 \pm 1.0$ \\
\hline
\end{tabular}

Stomach

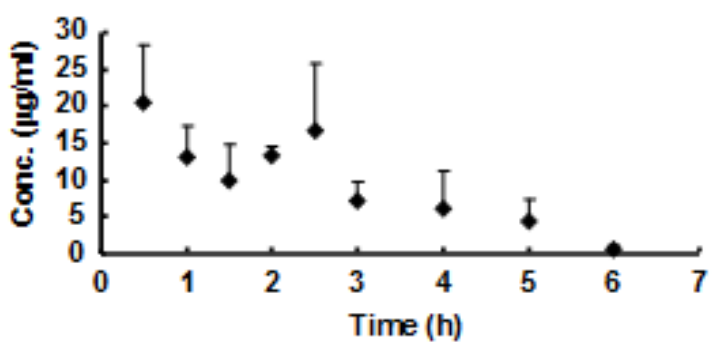

Lower small intestine

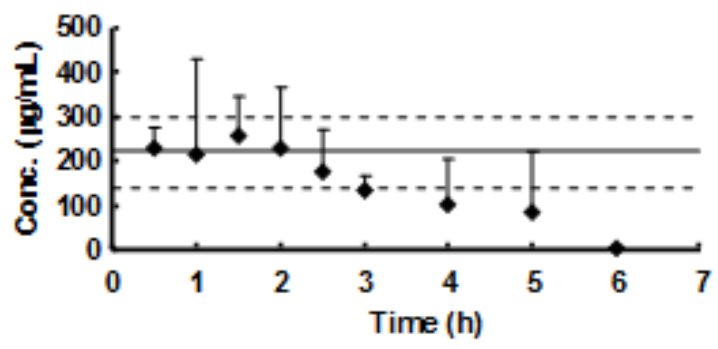

Upper small intestine

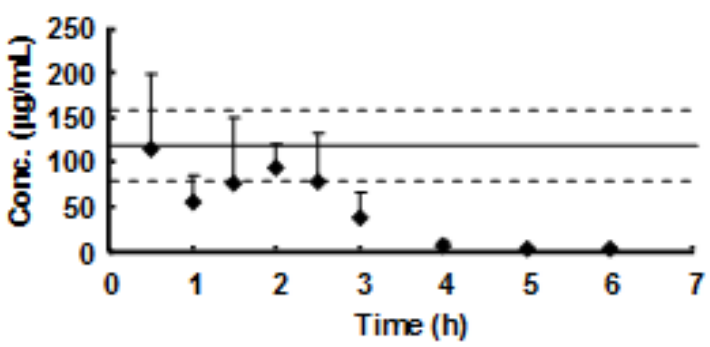

Colon

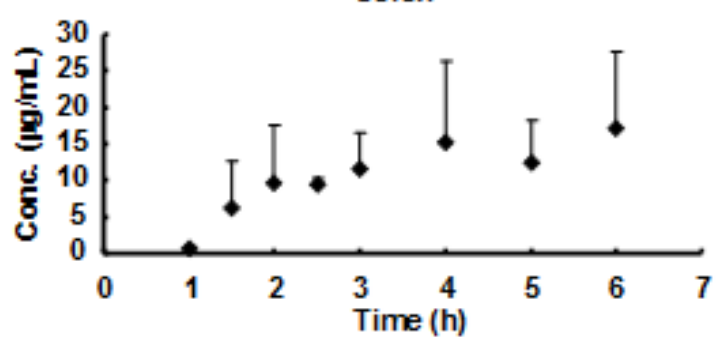

Figure 2. Luminal GF concentrations after oral administration. The results are expressed as the mean $\pm \mathrm{SD}(\mathrm{N}=4)$.

This is because that one of the four upper intestinal samples at $4 \mathrm{~h}$ obtained from rats showed much higher AZ concentration, and it might be attributed to large individual difference in intestinal transit of drug particles. In colon, the GF and $\mathrm{AZ}$ concentrations were much lower than those in upper and lower small intestine. This is due to much lower concentration of total bile acid and phospholipids concentration in colon. The total bile acid and phospholipids concentrations were about 50 and $3.7 \mathrm{mM}$ in upper small intestine and 100 and $0.1 \mathrm{mM}$ in lower small intestine, respectively (12). These concentrations in colon was determined by same methods reported in our previous work (12), and the total bile acid concentration was $9.2 \pm$ 4.0 $\mathrm{mM}$, and no phospholipids were detected in colonic fluid.

\section{Plasma GF and AZSO concentration and the PK parameters}

The plasma concentration-time profiles after oral and i.v. administration of GF are shown in Fig. 4A and $\mathrm{B}$, and the pharmacokinetics parameters are summarized in Table 3 . The AUC values after oral administration of $25 \mathrm{mg}$ GF suspension and $0.5 \mathrm{mg}$ GF solution were 7.53 ( $\mathrm{AUC}_{0-\infty}$, suspension, sys $)$ and 0.421 ( $\mathrm{AUC}_{0-\infty}$, solution, sys $) \mu \mathrm{g} \times \mathrm{h} / \mathrm{mL}$, respectively, in the systemic plasma and $14.2\left(\mathrm{AUC}_{0-\infty}\right.$, suspension, pv $)$ and $0.875\left(\mathrm{AUC}_{0-\infty}\right.$, solution, $\left.\mathrm{pv}\right) \mu \mathrm{g} \times \mathrm{h} / \mathrm{mL}$, respectively, in the portal plasma. No GF was determined in the lower small intestinal fluid after oral administration of $0.5 \mathrm{mg}$ of GF solution, indicating GF was completely absorbed (data not shown), and therefore $\mathrm{Fa}_{\text {solution }}$ could be assumed to be 1 . The AUC was $1.44 \mu \mathrm{g} \times \mathrm{h} / \mathrm{mL}$ after i.v. administration of $\mathrm{GF}$ solution $\left(\mathrm{AUC}_{0-\infty}\right.$, i.v $)$. 
$\mathrm{BA}_{\text {suspension }}$ and $\mathrm{BA}_{\text {solution }}$ values, calculated by comparing $\mathrm{AUC}_{0-\infty \text {, suspension, sys }}$ and $\mathrm{AUC}_{0-\infty \text {, solution, sys }}$ with $\mathrm{AUC}_{0-\infty}$, i.v., were $10.6 \%$ and $29.8 \%$, respectively. The non-linearity in GF metabolism in the liver after oral administration of GF suspension was observed, because the $\mathrm{Fh}_{\text {suspension }} / \mathrm{Fh}_{\text {solution }}$ value was about 1.22. In AZ (Fig 5 and Table 3), the AUC values estimated from AZSO concentration-time profiles after oral administration of $3.5 \mathrm{mg} \mathrm{AZ}$ suspension and i.v. administration of $0.2 \mathrm{mg}$ AZSO solution were 12.8 ( $\mathrm{AUC}_{0-\infty}$, suspension, sys $)$ and 3.01 $\left(\mathrm{AUC}_{0-\infty}\right.$, i.v. $) \mu \mathrm{g} \times \mathrm{h} / \mathrm{mL}$, respectively, and $\mathrm{BA}_{\text {suspension }}$ of AZ was $24.2 \%$. The AUC $(3.72 \mu \mathrm{g} \times$ $\mathrm{h} / \mathrm{mL}$ ) calculated from AZSO concentration-time profile after oral administration of $0.275 \mathrm{mg} \mathrm{AZ}$ solution $\left(\mathrm{AUC}_{0-\infty}\right.$, solution, sys $)$ was reported in our previous study (26), and used for estimation of $\mathrm{BA}_{\text {solution }}$ of $\mathrm{AZ}$. The value was $90 \%$. We measured the levels of intact $A Z$ after oral administration of AZ by using HPLC at the same time as AZSO quantification (data not shown). The HPLC conditions for $\mathrm{AZ}$ have been reported previously (27). Although a very low concentration of $A Z$ was detected $\left(\mathrm{C}_{\max }\right.$ values were 0.06 and $0.04 \mu \mathrm{g} / \mathrm{mL}$ after oral administration of $3.5 \mathrm{mg}$ and $0.275 \mathrm{mg}$ of $\mathrm{AZ}$ as suspension and solution, respectively.), it is considered to be negligible level and therefore, it was indicating almost $100 \%$ of $\mathrm{AZ}$ absorbed across the GI tract was metabolized into AZSO.

\section{Fa values}

In vivo and predicted Fa values are shown in Table

Stomach

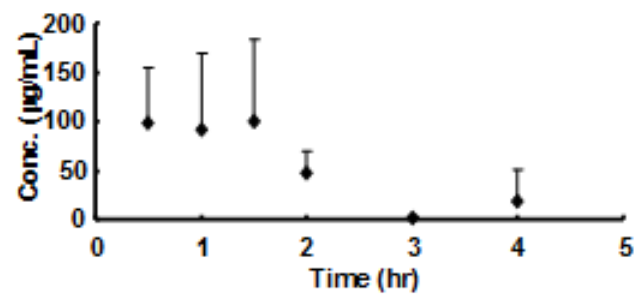

Lower small intestine

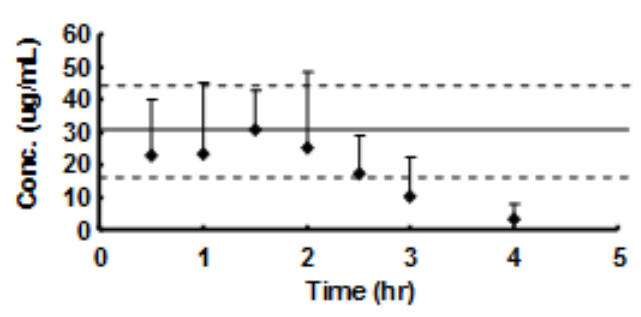

4. The equation for MAD used for estimation of predicted $\mathrm{Fa}$ in this study can estimate absorbed drug amount only under solubility-limited absorption (In other words, under condition that luminal drug concentration sustains the saturated solubility) and the GF and AZ concentration in the lower small intestine after oral administration of these suspensions sustained the saturated solubility until $3 \mathrm{~h}$ and $2.5 \mathrm{~h}$, respectively. Therefore, the predicted $\mathrm{Fa}$ values at time $3 \mathrm{~h}\left(\mathrm{Fa}_{\text {predicted, } 3 \mathrm{~h}}\right)$ for $\mathrm{GF}$ and at time $2.5 \mathrm{~h}\left(\mathrm{Fa}_{\text {predicted, } 2.5 \mathrm{~h}}\right)$ for $\mathrm{AZ}$ were calculated using the apparent permeability and saturated solubility of GF and AZ, estimated using two different types of simulated GI fluid, the surface area, and the duration of saturated GF and $\mathrm{AZ}$ in each GI segment (GF and $\mathrm{AZ}$ dose $=25$ and $3.5 \mathrm{mg}$, respectively). In addition, Fa values at time $\mathrm{t}$ were also predicted only using permeability and saturated solubility data of GF and AZ estimated

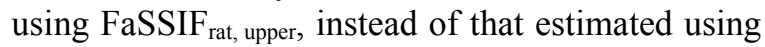
FaSSIF $_{\text {rat, lower }}\left(\mathrm{Fa}_{\text {predicted, upper, } t}\right)$, to evaluate the importance of consideration of regional difference in the drug dissolution and permeation for prediction of oral absorption. The predicted $\mathrm{Fa}$ values at $3 \mathrm{~h}$ for $\mathrm{GF}\left(\mathrm{Fa}_{\text {predicted, } 3 \mathrm{~h}}\right.$ and $\mathrm{Fa}_{\text {predicted, upper, }}$

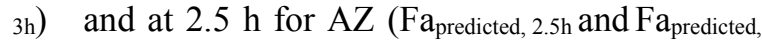
upper, $2.5 \mathrm{~h})$ were calculated by adopting $\mathrm{t}_{\text {upper }}(2.5 \mathrm{~h}$ or $1 \mathrm{~h})$ and $\mathrm{t}_{\text {lower }}(3 \mathrm{~h}$ or $2.5 \mathrm{~h})$, respectively. To compare with predicted $\mathrm{Fa}$ values of $\mathrm{GF}$ and $\mathrm{AZ}$,

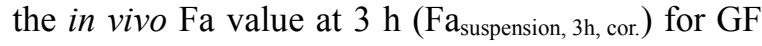
and at $2.5 \mathrm{~h}\left(\mathrm{Fa}_{\text {suspension, } 2.5 \mathrm{~h}}\right)$ for $\mathrm{AZ}$ were calculated using equations (5) and (8) and/or (13).

Upper small intestine
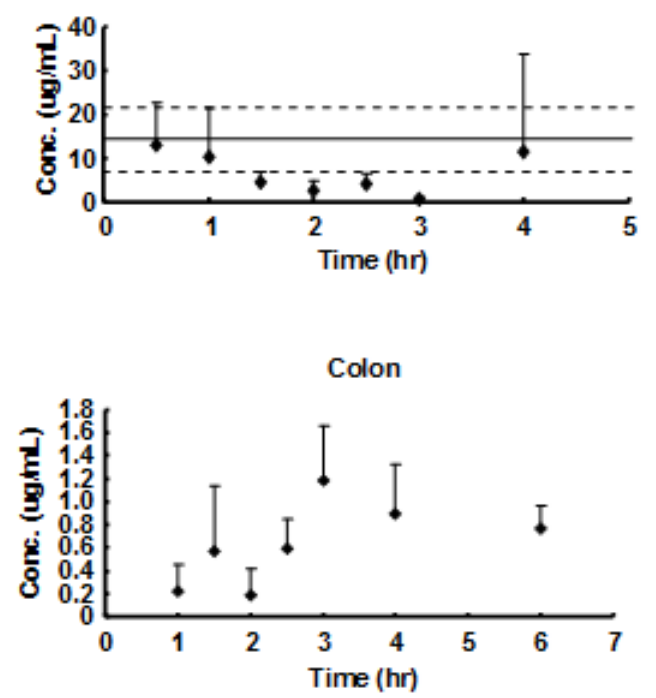

Figure 3. Luminal $A Z$ concentrations after oral administration. The results are expressed as the mean $\pm \mathrm{SD}(\mathrm{N}=4)$. 
A

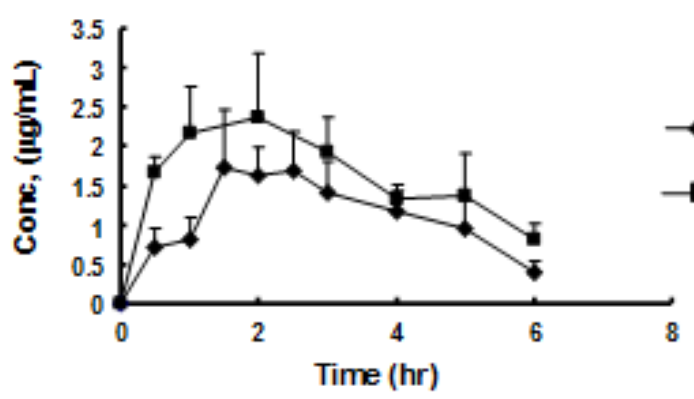

B

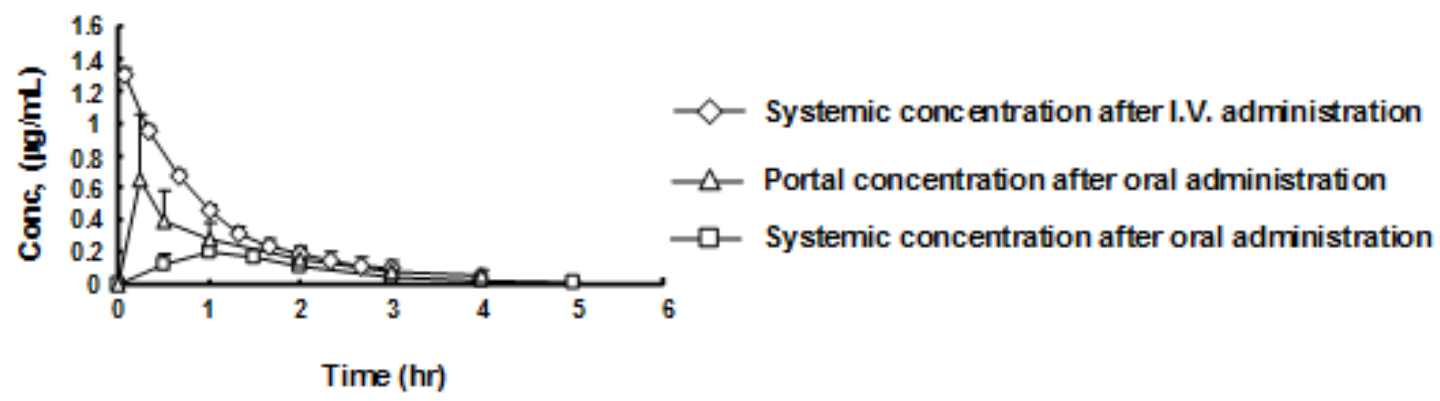

Figure 4. Systemic and portal plasma GF concentration-time courses after oral and i.v. administration. A; suspension $(25 \mathrm{mg} /$ body, $\mathrm{N}=4)$, B; solution $(0.5 \mathrm{mg} /$ body, $\mathrm{N}=5-6)$. The results are expressed as the mean $\pm \mathrm{SD}$.

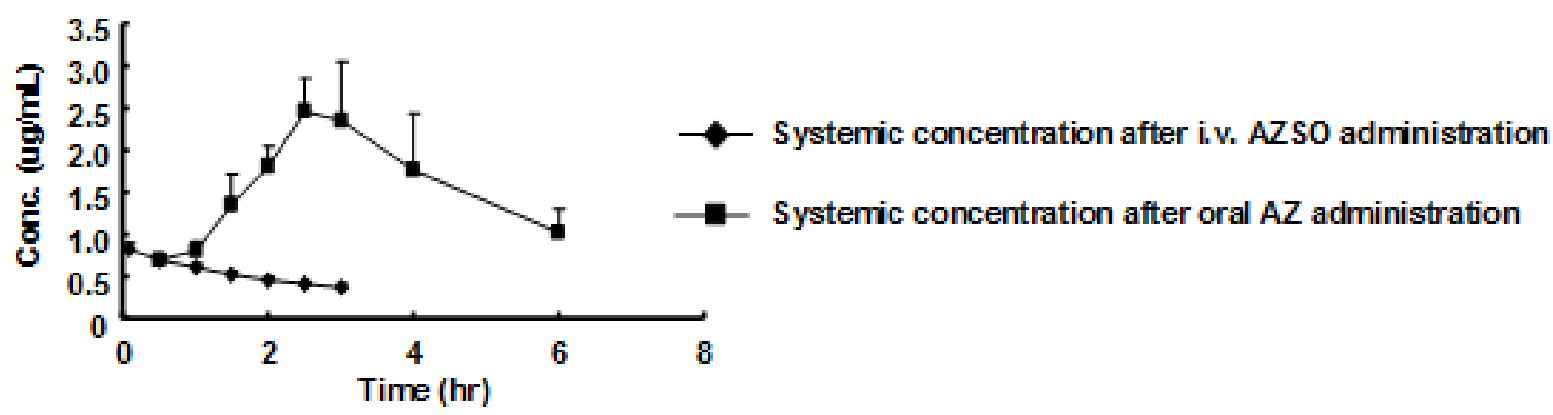

Figure 5. Plasma AZSO concentration-time courses after oral AZ administration as suspension (3.5mg) and i.v. AZSO administration $(0.2 \mathrm{mg})$. The results are expressed as the mean $\pm \mathrm{SD}(\mathrm{N}=4)$.

The $\mathrm{Fa}_{\text {predicted, } 3 \mathrm{~h}}$ of GF was $17.6 \%$. This was very

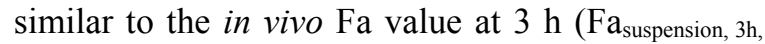
cor., 20.8\%). In contrast, the predicted $\mathrm{Fa}$ value at 3 $\mathrm{h}$ estimated using FaSSIF rat, upper $\left(\mathrm{Fa}_{\text {predicted, upper, 3h }}\right)$ alone was $11.5 \%$, only about half the in vivo $\mathrm{Fa}$

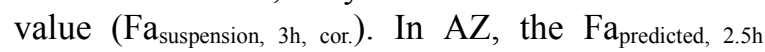
(24.5\%) was comparable with the $\mathrm{Fa}_{\text {suspension, } 2.5 \mathrm{~h}}$ $(25.6 \%)$ as well as GF, and the Fapredicted, upper, 2.5h $(11.1 \%)$ considerably underestimated the in vivo $\mathrm{Fa}$ of $\mathrm{AZ}$ at $2.5 \mathrm{~h}$. These data demonstrated that consideration of regional differences in GF dissolution and permeation using simulated GI fluid tailored to each part of the GI tract gave better prediction accuracy for in vivo Fa than predictions using simulated upper GI tract fluid only. The predicted $\mathrm{Fa}$ values in the upper and lower small intestine were 5.2 and $12.4 \%$ in GF, and 3.2 and

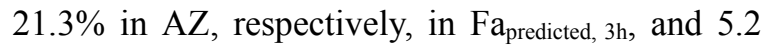
and $6.3 \%$ in GF, and 3.2 and $7.9 \%$ in $\mathrm{AZ}$, respectively, in $\mathrm{Fa}_{\text {predicted, upper, } 3 \mathrm{~h} \text {. }}$ 
Table 3. Phamacokinetic parameters

$\begin{array}{ccc}\text { Parameters } & \mathrm{GF} & \mathrm{AZ} \mathrm{or} \mathrm{AZSO} \\ \mathrm{AUC}_{0-\infty \text {, suspension, sys }} & 7.53 \mu \mathrm{g} \times \mathrm{h} / \mathrm{mL} & 12.8 \mu \mathrm{g} \times \mathrm{h} / \mathrm{mL}^{\mathrm{a}} \\ \mathrm{AUC}_{0-\infty \text {, solution, sys }} & 0.421 \pm 0.093 \mu \mathrm{g} \times \mathrm{h} / \mathrm{mL} & 3.72 \pm 0.62 \mu \mathrm{g} \times \mathrm{h} / \mathrm{mL}^{\mathrm{b}} \\ \mathrm{AUC}_{0-\infty, \text { i.v. }} & 1.44 \pm 0.21 \mu \mathrm{g} \times \mathrm{h} / \mathrm{mL} & 3.01 \pm 0.48 \mu \mathrm{g} \times \mathrm{h} / \mathrm{mL}^{\mathrm{a}} \\ \mathrm{AUC}_{0-\infty, \text { suspension, pv }} & 14.2 \mu \mathrm{g} \times \mathrm{h} / \mathrm{mL} & - \\ \mathrm{AUC}_{0-\infty, \text { solution, pv }} & 0.875 \mu \mathrm{g} \times \mathrm{h} / \mathrm{mL} & - \\ \mathrm{BA}_{\text {suspension }} & 10.6 \% & 24.2 \% \mathrm{c}^{\mathrm{c}} \\ \mathrm{BA}_{\text {solution }} & 29.8 \% & 90 \% \mathrm{c}^{\mathrm{c}} \\ \mathrm{Fh}_{\text {suspension }} / \mathrm{Fh}_{\text {solution }} & 1.22 & -\end{array}$

${ }^{a}$ The AUC calculated from AZSO concentration-time profile after oral AZ administration as suspension (AUC $\mathrm{A}_{0-\infty}$, suspension, sys $)$ and i.v. AZSO administration $\left(\mathrm{AUC}_{0-\infty}\right.$, i.v.).

${ }^{\mathrm{b}}$ The AUC calculated from AZSO concentration-time profile after oral administration of $0.275 \mathrm{mg}$ of $\mathrm{AZ}$ as solution (26).

${ }^{c}$ Calculated based on the AUCs from plasma AZSO concentration after iv administration of AZSO and oral administration of $\mathrm{AZ}$ as suspension or solution. In the present study, in the case of AZ, the BA was defined as the rate of AZSO amount reaching systemic circulation to oral dosage of AZ.

Table 4. In vivo and predicted Fa values in each GI segment

\begin{tabular}{|c|c|c|c|c|}
\hline & & $\begin{array}{l}\text { Upper small } \\
\text { intestine }\end{array}$ & $\begin{array}{l}\text { Lower small } \\
\text { intestine }\end{array}$ & Total Fa \\
\hline \multirow[t]{3}{*}{ GF } & In vivo $\mathrm{Fa}_{\text {suspension, } 3 \mathrm{~h} \text {, cor. }}$ & & & $20.8 \%$ \\
\hline & $\begin{array}{l}\mathrm{Fa}_{\text {predicted, } 3 \mathrm{~h}} \text { and the composition in each GI } \\
\text { segment }\end{array}$ & $5.2 \%$ & $12.4 \%$ & $17.6 \%$ \\
\hline & $\begin{array}{l}\mathrm{Fa}_{\text {predicted, upper, } 3 \mathrm{~h}} \text { and the composition in each } \\
\text { GI segment }\end{array}$ & $5.2 \%$ & $6.3 \%$ & $11.5 \%$ \\
\hline \multirow[t]{3}{*}{$\mathrm{AZ}$} & In vivo $\mathrm{Fa}_{\text {suspension, } 2.5 \mathrm{~h}}$ & & & $25.6 \%$ \\
\hline & $\begin{array}{l}\mathrm{Fa}_{\text {predicted, } 2.5 \mathrm{~h}} \text { and the composition in each GI } \\
\text { segment }\end{array}$ & $3.2 \%$ & $21.3 \%$ & $24.5 \%$ \\
\hline & $\begin{array}{l}\mathrm{Fa}_{\text {predicted, upper, } 2.5 \mathrm{~h} \text { and the composition in }} \\
\text { each GI segment }\end{array}$ & $3.2 \%$ & $7.9 \%$ & $11.1 \%$ \\
\hline
\end{tabular}




\section{DISCUSSION}

Fasted state simulated GI fluids reflecting the properties of the upper and lower small intestine were developed $\left(\mathrm{FaSSIF}_{\text {rat, upper, }}\right.$, and $\left.\mathrm{FaSSIF}_{\text {rat, lower }}\right)$ in order to predict the fraction of GF and $\mathrm{AZ}$ absorbed (Fa) in vivo. The predicted $\mathrm{Fa}$ value generated using these simulated GI fluids was compared with the in vivo $\mathrm{Fa}$, and the utility of this method for prediction of in vivo $\mathrm{Fa}$ value was evaluated.

Masaoka et al. evaluated apparent intestinal permeability of GF in micelle-free solution by in situ single pass perfusion method, and the value in jejunum $\left(0.909 \times 10^{-4} \mathrm{~cm} / \mathrm{sec}\right)$ were a little lower than those in ileum and colon (1.243 and $1.296 \times$ $10^{-4} \mathrm{~cm} / \mathrm{sec}$, respectively) (19). This is because that GF permeation across the GI membrane is limited mainly by unstirred water layer (UWL) (28), and the thickness is thicker in jejunum than those in ileum and colon (19). In the present study, the GF permeability estimated in $\mathrm{FaSSIF}_{\text {rat, }}$ upper and

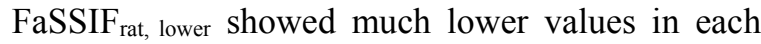
GI segment compared to those estimated in micelle-free solution, and the regional difference in the permeability disappeared (Table 2). It is generally considered that only the free drug concentration is available for transport across the membrane in the presence of mixed micelles (29, 30). Therefore, it is considered that the presence of mixed micelles in the simulated GI fluids decreased the free fraction of GF on the intestinal membrane surface, inducing the reduction of the apparent permeability in each GI segment.

However, assuming that only free drug is available for transport across the membrane, the lower GF permeability would be expected for FaSSIF $_{\text {rat, }}$ lower because of the high sodium taurocholate concentration and the low free GF fraction. However, GF permeability estimated using the simulated GI fluids was similar in each GI tract region, and regional differences in GI membrane permeability were not observed (Table 2). Amidon et al. reported that micelles assisted the transport of solubilized drug across the aqueous diffusion layer to the surface of the intestinal membrane, leading to a reduction in the resistance of the UWL to lipophilic drug absorption (31, 32). In addition, Yano et al. recently reported absorption of lipophilic drugs by direct partitioning into the intestinal membrane from the micellar phase, although the permeability was substantially lesser than that of free drug (33). Taken together, this might be because the reduction in apparent GF permeability due to the reduction in the free fraction was partially canceled out by reduced UWL resistance and direct GF permeation from the micellar phase. Therefore, the ratio of free to micellar drug concentrations is very important for estimation of in vivo intestinal drug permeability. The use of newly developed simulated GI fluids by taking regional differences into account can help improve estimation of drug membrane permeation. When intestinal permeability of a drug estimated in solution without micelles or of different micelle concentration from in vivo is used for prediction of oral absorption, the accuracy might be reduced. There are some reports to attempt the prediction of oral GF absorption in rats. Although the permeability of GF in micelle-free solution was estimated by in situ loop method and the data was used for the prediction in these report, the plasma GF concentration-time profiles has been well predicted. This is because that biorelevant media including much lower concentration of bile acids than the actual value was used to estimate the saturated GF solubility and the dissolution rate constant, and therefore it was considered that the overestimated apparent permeability of GF in micelle-free solution compensated underestimated the solubility or dissolution rate constant. In AZ, the permeability in lower small intestine was 1.25 times higher than that in upper small intestine (Table 2), although it was considered the free AZ

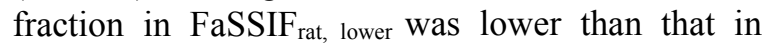

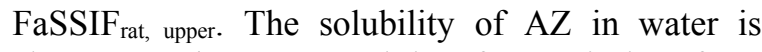
about $10 \mu \mathrm{g} / \mathrm{mL}$ (34), and therefore majority of $\mathrm{AZ}$ was considered to be present as free fraction in $\mathrm{FaSSIF}_{\text {rat, upper }}$ (the saturated AZ solubility was 14.9 $\mu \mathrm{g} / \mathrm{mL}$ ). In addition, $\mathrm{AZ}$ is more lipophilic compound than GF (34). Hence, AZ permeation across the upper small intestinal membrane in

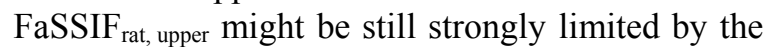
UWL, even though UWL resistance might be to some extent reduced by micelles.

The difference in duration of saturated solubility between GF and AZ was observed (Figs 2 and 3 ). This might be caused by the difference in their dose, physicochemical property of particle surface (interaction with GI membrane) and dissolution rate. According to the report from Masaoka et al., it took about 60 minutes for the administered drug to reach the maximum concentration in the lower intestine (19). However, 
in this study, the drugs concentration in the lower intestine reached the saturated solubility at very early time. This is because that GF and AZ are low soluble, and therefore even if only the small amount of administered drugs reach the lower intestinal segment at early time, it is enough amount for low soluble drugs to show the saturated solubility.

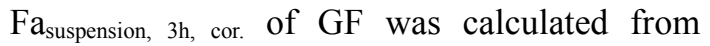
$\mathrm{Fa}_{\text {suspension, } 3 \mathrm{~h}}$ and $\mathrm{Fh}_{\text {suspension }} / \mathrm{Fh}_{\text {solution }}$ at infinite time was calculated by using equations (10)-(12). It is considered that the values of $\mathrm{Fh}_{\text {suspension }} / \mathrm{Fh}_{\text {solution }}$ are different at each time point after oral administration. However, $\mathrm{BA}_{\text {suspension }}$ was $10.6 \%$ and $\mathrm{BA}_{\text {suspension, } 3 \mathrm{~h}}$ was $7.6 \%$ (data not shown), and therefore, the absorption was almost completed by $3 \mathrm{~h}$. Hence, the value of $\mathrm{Fh}_{\text {suspension }} / \mathrm{Fh}_{\text {solution }}$ at infinite time was considered to be close to that at $3 \mathrm{~h}$.

Although it is also important to estimate $\mathrm{Fg}_{\text {suspension }} / \mathrm{Fg}_{\text {solution }}$ for evaluation of true $\mathrm{Fa}_{\text {suspension, }}$ 3h of GF, the calculation is too difficult under non-linear pharmacokinetics. However, $\mathrm{Fg}_{\text {suspension }} / \mathrm{Fg}_{\text {solution }}$ was considered to be almost 1 , because the luminal GF concentration easily reached the saturated solubility with the increase in the dose due to the low solubility of GF. In our previous study, we reported that the $C_{\max }$ value of the luminal GF concentration time-profile after oral administration of $2 \mathrm{mg} / 240 \mathrm{~g}$ of GF suspension to rats, under which the GF pharmacokinetics showed linearity, was about $60 \mu \mathrm{g} / \mathrm{mL}$ in the upper small intestinal lumen (26). This GF concentration was almost half the GF saturated solubility (about 100 $\mu \mathrm{g} / \mathrm{mL}$ ) in the upper luminal fluid (26). Although the GF dose used in this study (25 mg) was about 12.5 times higher than that used in previous study, the luminal GF concentration was only 2 times

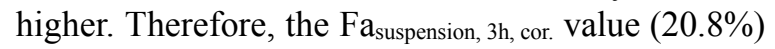
was considered to approach the true $\mathrm{Fa}_{\text {suspension, } 3 \mathrm{~h} \text {. In }}$ $\mathrm{AZ}, \mathrm{Fg} \times \mathrm{Fh}$ of AZSO in the first pass effect $\left(\mathrm{BA}_{\text {solution }}\right.$ of $\mathrm{AZ}$ ) was $90 \%$ (Table 3 ), meaning after $100 \%$ AZ was oxidized into AZSO in intestinal mucosa and liver, only $10 \%$ of the AZSO was metabolized into albendazole sulfone or other metabolites. Hence, if there was non-linearity in AZSO metabolism after oral administration of AZ suspension, the influence on the calculation of in vivo $\mathrm{Fa}$ of $\mathrm{AZ}$ is considered to be negligible.

Fasted state simulated rat colonic fluid $\left(\mathrm{FaSSCOF}_{\text {rat }}\right)$ was prepared based on total bile acid and phospholipid concentrations $(9.2 \pm 4.0 \mathrm{mM}$ and $0 \mathrm{mM}$, respectively.) and the $\mathrm{pH}$ to predict $\mathrm{GF}$ absorption at $3 \mathrm{~h}$ in colon by using the equation for $\operatorname{MAD}\left(\mathrm{Xa}_{\text {colon, } 3 \mathrm{~h}}=\mathrm{P}_{\text {colon }} \times \mathrm{Cs}_{\text {colon }} \times \mathrm{S}_{\text {colon }} \times \mathrm{t}_{\text {colon }}\right)$. The $\mathrm{pH}$ of colonic fluid (6.6) was determined by insertion of $\mathrm{pH}$ spear (Nikko Hansen \& Co., Ltd., Osaka, Japan) into the partly cut colonic lumen. Cholic acid (4.5 $\mathrm{mM}$ ) and deoxycholic acid (4.5 $\mathrm{mM}$ ) were selected as components of bile acids in $\mathrm{FaSSCoF}_{\text {rat }}$, because these components account for about $20-35 \%$ of the bile acids in the region (35), although taurocholic acid is the dominant component of bile acid in the rat small intestine (36). The colonic permeability of GF dissolved in FaSSCoF rat $\left(\mathrm{P}_{\text {colon }}\right)$ and saturated GF solubility in $\mathrm{FaSSCoF}_{\text {rat }}\left(\mathrm{Cs}_{\text {colon }}\right)$ were $3.6 \pm 0.51 \mathrm{~cm} / \mathrm{sec}$ and $26.7 \pm 0.58 \mu \mathrm{g} / \mathrm{mL}$, respectively. GF concentration in colonic fluid at $6 \mathrm{~h}(17.1 \pm 10.4 \mu \mathrm{g} / \mathrm{mL}$, Fig 2) was similar to the saturated GF solubility in FaSSCoF rat. Colonic lengths $(15.4 \pm 1.0 \mathrm{~cm})$ were directly measured using a ruler, and the surface area in colon was calculated by using a radius of 0.25 $\mathrm{cm}\left(\mathrm{Cs}_{\text {colon, }} 24.1 \mathrm{~cm}^{2}\right) \mathbf{( 2 0 )}$. In colon, the GF started to appear $1.5 \mathrm{~h}$ after oral administration (Fig. 2). Therefore, the duration time of the GF saturated solubility in colon was regarded as $1.5-3.0 \mathrm{~h}$ for estimation of the fraction GF absorbed from the colon over $3 \mathrm{~h}\left(\mathrm{Fa}_{\text {colon, } 3 \mathrm{~h}}=\mathrm{Xa} \mathrm{a}_{\text {colon, } 3 \mathrm{~h}} / \mathrm{Dose}\right)$. As a

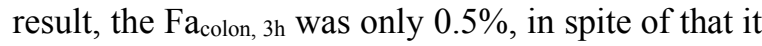
is assumed GF concentration sustained the saturated solubility in the colon from $1.5 \mathrm{~h}$ to $3 \mathrm{~h}$, although GF did not actually reach saturated solubility in the colon until $3 \mathrm{~h}$. It may be due to much lower GF concentration in colon compared to those in upper and small intestine. AZ absorption in colon is also considered to be negligible until $3 \mathrm{~h}$. In the case of low soluble drugs, the contribution to colonic absorption might be low because of the low drug dissolution ability in colonic fluid.

The predicted $\mathrm{Fa}$ values at $3 \mathrm{~h}$ of $\mathrm{GF}$ and at $2.5 \mathrm{~h}$ of $\mathrm{AZ}$ in the upper and lower small intestine were estimated as 5.2 and $12.4 \%$ in GF and 3.2 and $21.3 \%$ in AZ, respectively, using FaSSIF $_{\text {rat, upper, and }}$ FaSSIF $_{\text {rat, lower }}$ (Table 4). This result showed that GF and AZ were mostly absorbed in the lower small intestine until $3 \mathrm{~h}$ after oral administration. When only FaSSIF rat, upper was employed for the prediction, the lower small intestine $\mathrm{Fa}$ value at $3 \mathrm{~h}$ was about half in GF (6.3\%) and one third in AZ (7.9\%) of the value estimated using FaSSIF $_{\text {rat, lower. This was }}$ caused by the higher GF solubility in FaSSIF rat, lower than in FaSSIF rat, upper as well as longer residence time of drugs in lower small intestine. In consideration of these factors, evaluation of 
solubility and permeability in lower intestinal region is much more important for prediction of oral absorption especially in low soluble compounds.

\section{CONCLUSIONS}

Simulated rat GI fluids reflecting the upper and lower small intestinal fluids were prepared to evaluate the regional differences in membrane permeability and solubility of GF and AZ, a model drug with poor water solubility. In addition, simulated colonic fluid was also developed to evaluate GF absorption in colon. Oral GF and AZ absorption in rats was predicted using these parameters and compared to actual absorption in vivo. Large regional differences were identified in oral absorption of model drugs, and the Fa values were predicted accurately. These results clearly indicated that use of fluids simulating not only the upper intestinal segment fluid, but also the lower segment fluid, was very important for reliable simulation of oral absorption of drugs with low aqueous solubility, because higher drug solubility and longer drug residence time in lower small intestine in addition to influence of regional difference in micelles concentration on drug intestinal permeability. This approach to $\mathrm{Fa}$ prediction using a range of simulated GI fluids will be very useful for oral drug development.

\section{REFERENCES}

1. Tsume Y, Langguth P, Garcia-Arieta A, Amidon GL. In silico prediction of drug dissolution and absorption with variation in intestinal $\mathrm{pH}$ for BCS class II weak acid drugs: ibuprofen and ketoprofen. Biopharm Drug Dispos, 2012; 33: 66-77.

2. Paixão P, Gouveia LF, Morais JA. Prediction of the human oral bioavailability by using in vitro and in silico drug related parameters in a physiologically based absorption model. Int J Pharm, 2012;15: 84-98.

3. Sinha VK, Snoeys J, Osselaer NV, Peer AV, Mackie C, Heald D. From preclinical to human--prediction of oral absorption and drug-drug interaction potential using physiologically based pharmacokinetic (PBPK) modeling approach in an industrial setting: a workflow by using case example. Biopharm Drug Dispos, 2012; 33: 111-21.
4. Thelen K, Coboeken K, Willmann S, Burghaus R, Dressman JB, Lippert J. Evolution of a detailed physiological model to simulate the gastrointestinal transit and absorption process in humans, part 1: oral solutions. J Pharm Sci, 2011; 100: 5324-45.

5. Wiedmann TS, Kamel L. Examination of the solubilization of drugs by bile salt micelles. J Pharm Sci, 2002; 91: 1743-64.

6. Kleberg K, Jacobsen F, Fatouros DG, Müllertz A. Biorelevant media simulating fed state intestinal fluids: colloid phase characterization and impact on solubilization capacity. J Pharm Sci, 2010; 99: 3522-32.

7. Rupp C, Steckel H, Müller BW. Solubilization of poorly water-soluble drugs by mixed micelles based on hydrogenated phosphatidylcholine. Int J Pharm, 2010; 395: 272-80.

8. Galia E, Nicolaides E, Hörter D, Löbenberg R, Reppas C, Dressman JB. Evaluation of various dissolution media for predicting in vivo performance of class I and II drugs. Pharm. Res, 1998; 15: 698-705.

9. Dressman JB, Reppas C. In vitro-in vivo correlations for lipophilic, poorly water-soluble drugs. Eur J Pharm Sci, 2000;11: S73-80.

10. Jantratid E, Janssen N, Chokshi H, Tang K, Dressman JB. Designing biorelevant dissolution tests for lipid formulations: case example--lipid suspension of RZ-50. Eur J Pharm Biopharm, 2008; 69: 776-85.

11. Scholz A, Kostewicz E, Abrahamsson B, Dressman JB. Can the USP paddle method be used to represent in-vivo hydrodynamics? J Pharm Pharmacol, 2003; 55: 443-51.

12. Tanaka Y, Hara $T$, Waki R, Nagata S. Regional differences in the components of luminal water from rat gastrointestinal tract and comparison with other species. J Pharm Pharm Sci, 2012; 15: 510-8.

13. Fotaki N, Symillides M, Reppas C. In vitro versus canine data for predicting input profiles of isosorbide-5-mononitrate from oral extended release products on a confidence interval basis. Eur J Pharm Sci, 2005; 24: 115-22.

14. Jantratid E, De Maio V, Ronda E, Mattavelli V, Vertzoni M, Dressman JB. Application of biorelevant dissolution tests to the prediction of in vivo performance of diclofenac sodium from an oral modified-release pellet dosage form. Eur J Pharm Sci, 2009; 37: 434-41.

15. Johnson, KC, Swindell AC. Guidance in the setting of drug particle size specifications to minimize variability in absorption. Pharm Res, 1996;13: 
1795-8.

16. Ozaki S, Minamisono $\mathrm{T}$, Yamashita $\mathrm{T}$, Kato $\mathrm{T}$, Kushida I. Supersaturation-nucleation behavior of poorly soluble drugs and its impact on the oral absorption of drugs in thermodynamically high-energy forms. J Pharm Sci, 2012; 101: 214-22.

17. Takano R, Furumoto K, Shiraki K, Takata N, Hayashi Y, Aso Y, Yamashita S. Rate-limiting steps of oral absorption for poorly water-soluble drugs in dogs; prediction from a miniscale dissolution test and a physiologically-based computer simulation. Pharm Res, 2008; 25: 2334-2344.

18. Takano R, Takata N, Saito R, Furumoto K, Higo S, Hayashi Y, Machida M, Aso Y, Yamashita S. Quantitative Analysis of the Effect of Supersaturation on in Vivo Drug Absorption. Mol Pharm, 2010; 7: 1431-1440.

19. Masaoka Y, Tanaka Y, Kataoka M, Sakuma S, Yamashita S. Site of drug absorption after oral administration: assessment of membrane permeability and luminal concentration of drugs in each segment of gastrointestinal tract. Eur J Pharm Sci, 2006; 29: 240-50.

20. Fagerholm U, Lindahl A, Lennernäs H. Regional intestinal permeability in rats of compounds with different physicochemical properties and transport mechanisms. J Pharm Pharmacol, 1997; 49: 687-90.

21. DW Gottschall, VJ Theodorides, R Wang. The metabolism of benzimidazole anthelmintics. Parasitol. Today, 1990; 6: 118-124.

22. Schipper HG, Koopmans RP, Nagy J, Butter JJ, Kager PA, Van Boxtel CJ. Effect of dose increase or cimetidine co-administration on albendazole bioavailability. Am. J. Trop. Med. Hyg, 2000; 63: 270-3.

23. Kosaka K, Sakai N, Endo Y, Fukuhara Y, Tsuda-Tsukimoto M, Ohtsuka T, Kino I, Tanimoto T, Takeba N, Takahashi M, Kume T. Impact of intestinal glucuronidation on the pharmacokinetics of raloxifene. Drug Metab Dispos, 2011; 39: 1495-502.

24. Matsuda Y, Konno Y, Satsukawa M, Kobayashi T, Takimoto Y, Morisaki K, Yamashita S. Assessment of intestinal availability of various drugs in the oral absorption process using portal vein-cannulated rats. Drug Metab Dispos, 2012; 40: 2231-8.

25. Jung H, Medina L, García L, Fuentes I, Moreno-Esparza R. Absorption studies of albendazole and some physicochemical properties of the drug and its metabolite albendazole sulphoxide. J. Pharm. Pharmaco, 1998; 50: 43-8.

26. Tanaka Y, Waki R, Nagata S. Species differences in the dissolution and absorption of griseofulvin and albendazole, Biopharmaceutics Classification System class II drugs, in the gastrointestinal tract. Drug Metab Pharmacokinet, 2013; in press.

27. Tanaka Y, Inkyo M, Yumoto R, Nagai J, Takano M, Nagata $S$. Evaluation of in vitro dissolution and in vivo oral absorption of drug nanopowders prepared by novel wet-milling equipment. Current Nano Science, 2010; 6: 571-576.

28. Sugano K, Kataoka M, Mathews Cda C., Yamashita S. Prediction of food effect by bile micelles on oral drug absorption considering free fraction in intestinal fluid. Eur J Pharm Sci, 2010; 40: 118-24.

29. Chiu YY, Higaki K, Neudeck BL, Barnett JL, Welage LS, Amidon GL. Human jejunal permeability of cyclosporin A: influence of surfactants on P-glycoprotein efflux in Caco-2 cells. Pharm Res, 2003; 20: 749-56.

30. Katneni K, Charman SA., Porter CJ. Permeability assessment of poorly water-soluble compounds under solubilizing conditions: the reciprocal permeability approach. J Pharm Sci, 2006; 95: 2170-85.

31. Amidon GE, Higuchi WI, Ho NF. Theoretical and experimental studies of transport of micelle-solubilized solutes. J Pharm Sci, 1982; 71: 77-84.

32. Dahan A, Miller JM, Hoffman A, Amidon GE, Amidon GL. The solubility-permeability interplay in using cyclodextrins as pharmaceutical solubilizers: mechanistic modeling and application to progesterone. J Pharm Sci, 2010; 99: 2739-49.

33. Yano K, Masaoka Y, Kataoka M, Sakuma S, Yamashita S. Mechanisms of membrane transport of poorly soluble drugs: role of micelles in oral absorption processes. J Pharm Sci, 2010; 99: 1336-45.

34. Kasim NA, Whitehouse M, Ramachandran C, Bermejo M, Lennernäs H, Hussain AS, Junginger HE, Stavchansky SA, Midha KK, Shah VP, Amidon GL. Molecular properties of WHO essential drugs and provisional biopharmaceutical classification. Mol Pharm, 2004; 1: 85-96.

35. Hagio M, Matsumoto M, Fukushima M, Hara H, Ishizuka S. Improved analysis of bile acids in tissues and intestinal contents of rats using LC/ESI-MS. J Lipid Res, 2009; 50: 173-80.

36. Dongowski G., Huth M., Gebhardt E. Steroids in the intestinal tract of rats are affected by 
J Pharm Pharm Sci (www.cspsCanada.org) 17(1) 106 - 120, 2014

dietary-fibre-rich barley-based diets. $\mathrm{Br} \mathrm{J}$ Nutr,

2003; 90: 895-906. 